OPEN ACCESS

Edited by:

Andreas Charidimou, Massachusetts General Hospital and Harvard Medical School,

United States

Reviewed by:

Duangnapa Roongpiboonsopit, Naresuan University, Thailand

Ellis van Etten,

Leiden University Medical

Center, Netherlands

${ }^{*}$ Correspondence:

Xingquan Zhao

zxq@vip.163.com

Specialty section:

This article was submitted to

Stroke,

a section of the journal

Frontiers in Neurology

Received: 26 April 2019

Accepted: 30 July 2019

Published: 14 August 2019

Citation:

Wang $X$, Feng $H$, Wang $Y$, Zhou J and

Zhao $X$ (2019) Enlarged Perivascular

Spaces and Cerebral Small Vessel Disease in Spontaneous Intracerebral

Hemorrhage Patients.

Front. Neurol. 10:881

doi: 10.3389/fneur.2019.00881

\section{Enlarged Perivascular Spaces and Cerebral Small Vessel Disease in Spontaneous Intracerebral Hemorrhage Patients}

\author{
Xin Wang ${ }^{1}$, Hao Feng ${ }^{1}$, Yu Wang ${ }^{1}$, Jian Zhou ${ }^{2}$ and Xingquan Zhao ${ }^{1 *}$ \\ ${ }^{1}$ Department of Neurology, Beijing Tiantan Hospital, Capital Medical University, Beijing, China, ${ }^{2}$ Department of Radiology, \\ Beijing Tiantan Hospital, Capital Medical University, Beijing, China
}

Background: Cerebral small vessel disease (SVD) is associated with cognitive decline, depression, increased mortality, and disability in stroke patients. MRI-visible perivascular spaces (PVS) are a sensitive neuroimaging marker of SVD. We aimed to explore the risk factors and associations with other SVD markers of PVS in two topographical regions (in the basal ganglia [BG] and centrum semiovale [CS]) in a cohort of spontaneous intracerebral hemorrhage $(\mathrm{ICH})$ patients.

Method: We included 306 consecutive patients from a prospective spontaneous $\mathrm{ICH}$ cohort. We rated PVS, white matter hyperintensities $(\mathrm{WMH})$, cerebral microbleeds (CMB), and lacunes with validated visual rating scale. We collected clinical information using standardized forms. We predefined severe PVS as score $>2$ and examined associations between PVS in both BG and CS regions and clinical and imaging markers of SVD by logistic regression.

Results: In the multivariable logistic regression, increasing age $(\mathrm{OR}=1.075 ; 95 \% \mathrm{Cl}=$ $1.038-1.113, p<0.001)$, high CS PVS degrees (OR $=6.906 ; 95 \% \mathrm{Cl}=3.024-15.774$, $p<0.001)$, extensive periventricular $\mathrm{WMH}(\mathrm{OR}=2.878$; 95\% $\mathrm{Cl}=1.298-6.379, p=$ 0.009), and the presence of $\mathrm{CMB}(\mathrm{OR}=4.073,95 \% \mathrm{Cl}=1.869-8.877, p<0.001)$ were independently associated with BG PVS severity. Alcohol-drinking habit $(\mathrm{OR}=2.805$; $95 \% \mathrm{Cl}=1.451-5.422, p=0.002)$, hyperlipidemia history $(\mathrm{OR}=3.782 ; 95 \% \mathrm{Cl}=$ $1.582-8.783, p=0.003)$, high BG PVS degrees $(\mathrm{OR}=6.293 ; 95 \% \mathrm{Cl}=2.755-14.371$, $p<0.001)$ and the presence of strictly lobar $\mathrm{CMB}(\mathrm{OR}=2.556,95 \% \mathrm{Cl}=1.285-5.085$, $p=0.008$ ) were independent predictors of increased CS PVS severity.

Conclusion: MRI-visible PVS in BG and CS regions are inter-related and have different risk factors in spontaneous $\mathrm{ICH}$ patients. Further studies are needed to explore the mechanism and clinical importance of PVS, with possible implications for cerebrovascular disease prevention and effective treatments.

Keywords: cerebral small vessel disease, perivascular spaces, intracerebral hemorrhage, risk factors, MRI 


\section{INTRODUCTION}

Spontaneous (non-traumatic) intracerebral hemorrhage (ICH) is a devastating neurological disorder resulting from ruptured blood vessels in the brain (1). ICH is the second most common subtype of stroke (10-15\%) and accounts for 2 million strokes worldwide each year (2). However, ICH is the most severe subtype of stroke because of its high fatality case rate and poor functional outcome; the median case fatality is $40.4 \%$ at 1 month (1).

Perivascular spaces (PVS), or Virchow-Robin spaces, are fluid-containing spaces that surround the walls of arteries, arterioles, veins, and venules as they course from the subarachnoid space into the brain parenchyma $(3,4)$. PVS are round or linear delineated structures seen on MRI with intensities close to cerebrospinal fluid (CSF) and $<3 \mathrm{~mm}$ diameter in cross section (3), and are defined as having a diameter "smaller than $3 \mathrm{~mm}$ when imaged perpendicular to the course of the vessel" in the STRIVE guidelines to aid the description of cerebral small vessel disease (SVD) features (5).

PVS may function as fluid circulation and drainage pathways for the efficient exchange of essential nutrients and efficient removal of metabolic waste and cell debris through the central nervous system (6). Though the concept of the "glymphatic system" (7) is controversial $(6,8)$, this perivascular pathway is important for maintaining brain homeostasis. Increasing visibility of PVS on MRI are associated with increasing age, hypertension (9), stroke, other SVD features such as lacunar stroke and white matter hyperintensities (WMH) (10), systemic inflammation (11), multiple sclerosis (4), cognitive impairment, and dementia (12-14).

In $\mathrm{ICH}$ patients, hematomas form rapidly after vessel rupture and lead to a sharp increase in intracranial pressure, which causes primary brain injury. Inflammation begins immediately after the hematoma formation and contributes to secondary brain injury. Immune cells recruitment and infiltration into brain parenchyma is the key step of inflammation initiation and progression (15). PVS are specific sites for immune cell accumulation, reaction, and transmigration into the brain parenchyma (e.g., leukocytes, dendritic cells, T-cells, B-cells, and macrophages (16-18). PVS may provide imaging evidence of vascular and inflammatory changes in the brain after ICH. However, currently there are not many studies that have systematically researched the importance of PVS in spontaneous ICH population $(19,20)$. Thus, in this study, we aim to investigate the special distribution and severity of PVS in spontaneous ICH patients, and to explore their clinical risk factors and associations with other SVD imaging markers, using structural magnetic resonance imaging (MRI).

\section{MATERIALS AND METHODS}

\section{Study Population and Data Collection}

For this cross-sectional analysis, we used prospectively collected data from a study of consecutive patients older than 18 years old with spontaneous symptomatic ICH admitted at the Beijing Tiantan Hospital and underwent computed tomography (CT) scans $(N=883)$ from June 2014 to October 2016. Patients were excluded from the study if they did not undergo MRI scans ( $N$ $=519$ ). Spontaneous symptomatic ICH was confirmed by nonenhanced CT scans showing parenchymal bleeding. Patients were also excluded if they were diagnosed with secondary ICH $(N$ $=46$ ), including brain tumor, head trauma, aneurysm, vascular malformation, hemorrhagic infarction, venous infarction, and Moyamoya disease. Patients underwent MRI scans, but those with poor image quality were also excluded $(N=12)$ as further analysis could not be properly performed.

We finally included 306 patients diagnosed as spontaneous ICH (Figure 1). All patients participating in this study provided written informed consent. The Beijing Tiantan Hospital Ethics Committee approved this study. Trained stroke physicians collected detailed patient information by using standard questionnaires at presentation. Age, gender, and clinical history (hypertension, diabetes, hypercholesterolemia, cerebral infarction, intracerebral hemorrhage (ICH), subarachnoid hemorrhage, transient ischemic attack (TIA), atrial fibrillation, myocardial infarction, heart failure and other heart disease, and peripheral vascular disease) were systematically recorded for each patient. Cigarette smoking was classified as never, previous, or current smokers, and alcohol drinking was classified as current drinker or non-drinker. Patients underwent CT, MRI, carotid imaging, and other investigations as required for following ICH treatment.

\section{Brain MRI Acquisition}

For all participants, MRI were performed within 6 days of admission. Images were obtained with two 3T MRI scanners, GE Discovery 750 scanner (GE Healthcare, Milwaukee, Wis) and Siemens verio scanner (Siemens, Erlangen, Germany). The MRI ICH protocols are similar in two MRI scanners, including the following sequences: whole brain T1 weighted image (T1W; repetition time/echo time $1,900 / 9.4 \mathrm{~ms} ; 5 \mathrm{~mm}$ slice thickness, $6 \mathrm{~mm}$ interslice gap), T2-weighted image (T2W; repetition

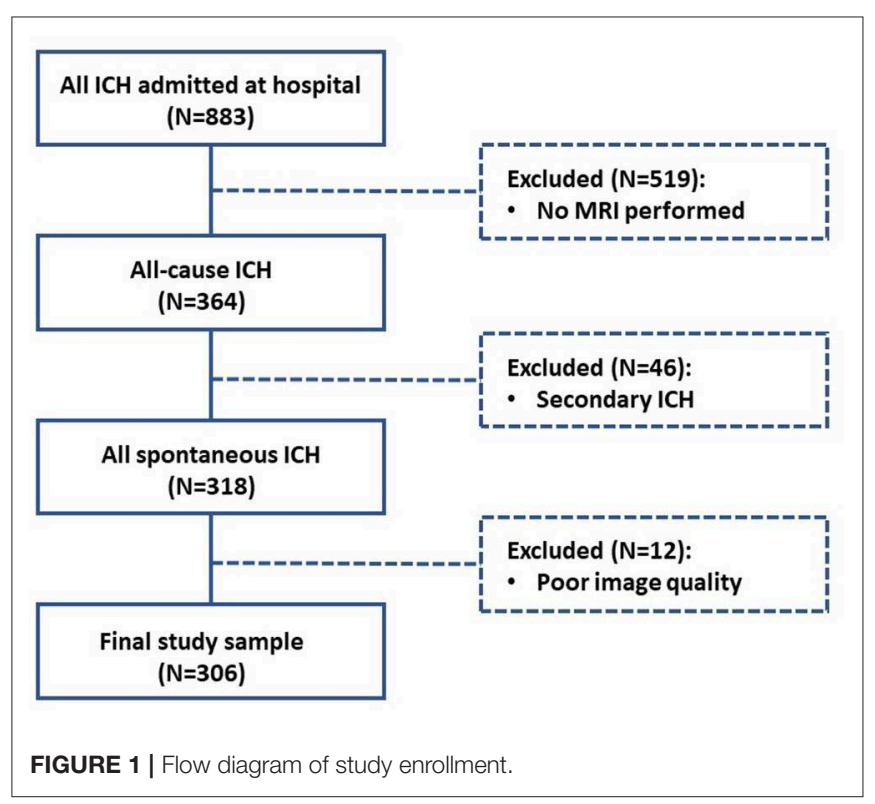


time/echo time $6,000 / 97 \mathrm{~ms}, 5 \mathrm{~mm}$ slice thickness, $6 \mathrm{~mm}$ interslice gap), and fluid-attenuated inversion recovery (FLAIR; repetition time/echo time $7,800 / 91 \mathrm{~ms}$, inversion time $2,200 \mathrm{~ms}$, $5 \mathrm{~mm}$ slice thickness, $6 \mathrm{~mm}$ interslice gap) and susceptibilityweighted imaging (SWI; repetition time/echo time $28 / 20 \mathrm{~ms}$, flip angle $15^{\circ}, 1.6 \mathrm{~mm}$ slice thickness, $0.3 \mathrm{~mm}$ interslice gap).

\section{Neuroimaging Analysis}

All neuroimaging analysis were performed and recorded according to STandards for ReportIng Vascular changes on nEuroimaging (STRIVE) guidelines (5) by trained image analysts blinded to patients' clinical characteristics. PVS were defined as $\leq 3 \mathrm{~mm}$ round or linear CSF isointensity lesions and were rated on axial $\mathrm{T} 2 \mathrm{~W}$ imaging with a validated visual rating scale $(10,21)$ : rated from 0 (none), 1 (1-10), 2 (11-20), 3 (21-40), and $4(>40)$ in both the basal ganglia (BG) and centrum semiovale (CS) regions. For both BG and CS regions, after going through all relevant slices for the anatomical area being assessed, we reviewed at least 3 adjacent slices with extensive PVS. One slice with the highest number of PVS was selected and the rating score on this selected slice was recorded. In cases with extensive WMH in the CS region, an estimate was made of the closest PVS rating category, using the appearance of non-involved white matter and cortical gray matter. When background brain parenchyma is asymmetric due to large lobar or deep ICH, PVS were rated in the contralateral hemisphere, and an estimate was made of the closest PVS rating category ipsilateral to the large lesion.

Lacunes were distinguished from PVS by larger size (3 15 $\mathrm{mm}$ ) on axial FLAIR imaging and defined as a subcortical round or ovoid fluid-filled cavity with a similar signal intensity as CSF (5). WMH are hyperintense lesions on FLAIR and T2W imaging and appear as hypointense on T1W imaging (5). We rated periventricular and deep $\mathrm{WMH}$ as $0-3$ with the Fazekas scale (22) on FLAIR or T2W imaging. Periventricular WMH was rated from 0 (none), 1 (pencil-thin lining), 2 (smooth halo), and 3 (irregular signal extending to the deep white matter). Deep WMH was rated from 0 (none), 1 (punctate foci), 2 (beginning confluence), and 3 (large confluent areas). Microbleeds were defined as small (generally $2-5 \mathrm{~mm}$ in diameter, but up to $10 \mathrm{~mm}$ ), rounded, or circular areas of signal void on susceptibility sensitive sequences. According to the Microbleed Anatomical Rating Scale (23), microbleeds were classified into deep, lobar, and infratentorial categories. Deep regions included the basal ganglia, thalamus, internal capsule, external capsule, corpus callosum, and deep and periventricular white matter; lobar regions included cortical and subcortical regions; infratentorial regions included the brainstem and cerebellum. We rated the number of microbleeds according to locations separately on SWI imaging and summed them up as total microbleeds. Microbleed mimics were carefully excluded using CT scans or T2W and FLAIR imaging. Basal ganglia calcification can mimic microbleeds and was excluded using CT scans. Mimics of sulcal vessel seen in cross section and partial volume artifact from adjacent bony structures were excluded by careful inspection of adjacent slices and reference to available T2W and FLAIR images.

All MRIs were assessed blinded to clinical information and the other rater's ratings. The interrater Cohen's kappa value for
BG PVS was 0.91 and CS PVS was 0.87 , for lacunes was 0.89 , for WMH was $0.86-0.89$, and for microbleeds was $0.83-0.90$.

\section{Statistical Analysis}

We classified the PVS burden as high (score 3 and 4) or low (score $0-2$ ) as suggested in previous studies $(9,20)$. We defined the extensive $\mathrm{WMH}$ as irregular periventricular $\mathrm{WMH}$ extending into the deep white matter (Fazekas score 3 ) or early confluent/confluent deep WMH (Fazekas score 2 or 3 ) as suggested previously $(24,25)$. Clinical and imaging characteristics of patients with high PVS degree vs. low PVS degree were compared in univariate analyses with the 2-sample $t$-test, Pearson's chi-squared test and Fisher exact test when appropriate. We subsequently evaluated independent predictors of high PVS degree in both BG and CS regions by logistic regression analyses based on univariable analyses results. Logistic regression models were run with a stepwise, forward-elimination method to generate a minimal adjusted model. All tests of significance were 2 tailed. Significance level was set at 0.05 for all analyses. SPSS software (SPSS for Windows, version 22.0, IBM-SPSS, Chicago, IL) was used for all analyses.

\section{RESULTS}

Our final cohort included 306 patients with spontaneous ICH. The mean age was $56.00( \pm 13.27)$ years old, ranging from 18 to 86 years old; the proportion of males was $71.57 \%$ (219 patients); and more than half of the cohort were current or previous smokers $(50.33 \%)$ and have the alcohol-drinking habit $(50.33 \%$, Table 1). In this cohort, $73.20 \%$ of patients had been diagnosed as hypertension previously, $13.73 \%$ had diabetes mellitus, and $11.11 \%$ have hypercholesterolemia problems. No patients had the history of TIA, myocardial infarction, heart failure, or peripheral vascular disease. Nearly $15 \%$ of patients had prior cerebral infarction, and seven patients had prior cerebral hemorrhage (seven ICH and one of them also had subarachnoid hemorrhage). Fifteen patients had heart diseases (4.90\%); including two patients who had atrial fibrillation $(0.65 \%$, Table 1$)$.

Table 1 also presents radiological characteristics of all $\mathrm{ICH}$ patients. According to the definitions and SVD scales used for visual rating, BG PVS (98.04\%), CS PVS (96.41\%), and periventricular WMH (95.42\%) were the most prevalent, followed by deep WMH $(87.25 \%)$, presence of microbleeds (50.98\%) and lacunes (43.46\%). The median BG PVS is 2 (interquartile range: IQR $=1-2$ ) and the median CS PVS is also $2(\mathrm{IQR}=1-2)$.

\section{Predictors of Increased BG PVS Severity in Spontaneous ICH Patients}

Demographic, vascular, and radiological characteristics of patients with high and low BG PVS degree are compared in Table 2. In univariable analyses, high BG PVS degree was significantly associated with increasing age $(p<0.001)$, hyperlipidemia history $(p=0.034)$, and baseline systolic blood pressure $(p=0.049)$. High BG PVS degree was also significantly associated high degree of PVS in CS region $(p<0.001)$, extensive $\mathrm{WMH}$ in both periventricular and deep regions (both $p<$ 
TABLE 1 | Baseline characteristics of all spontaneous ICH patients $(n=306)$.

\begin{tabular}{|c|c|}
\hline Characteristics & \\
\hline \multicolumn{2}{|l|}{ DEMOGRAPHICS } \\
\hline Mean age in years (SD) & $56.00(13.27)$ \\
\hline Male gender no. (\%) & $219(71.57 \%)$ \\
\hline \multicolumn{2}{|l|}{ VASCULAR RISK FACTORS } \\
\hline Ever-smokers no. (\%) & $154(50.33 \%)$ \\
\hline Alcohol drinking no. (\%) & $154(50.33 \%)$ \\
\hline Hypertension no. (\%) & $224(73.20 \%)$ \\
\hline Diabetes mellitus no. (\%) & 42 (13.73\%) \\
\hline Hyperlipidemia no. (\%) & $34(11.11 \%)$ \\
\hline Prior cerebral infarction no. (\%) & $44(14.38 \%)$ \\
\hline Prior intracerebral hemorrhage no. (\%) & $7(2.29 \%)$ \\
\hline Prior subarachnoid hemorrhage no. (\%) & $1(0.33 \%)$ \\
\hline Artial fibrillation no. (\%) & $2(0.65 \%)$ \\
\hline Other heart disease no. (\%) & $13(4.25 \%)$ \\
\hline Mean baseline SBP (SD) & $163.58(24.14)$ \\
\hline Mean baseline DBP (SD) & $95.38(17.53)$ \\
\hline \multicolumn{2}{|l|}{ SVD MARKERS } \\
\hline Basal ganglia PVS, median (IQR) & $2(1-2)$ \\
\hline Rating 0, no. (\%) & $6(1.96 \%)$ \\
\hline Rating 1, no. (\%) & $142(46.41 \%)$ \\
\hline Rating 2, no. (\%) & $107(34.97 \%)$ \\
\hline Rating 3, no. (\%) & $39(12.75 \%)$ \\
\hline Rating 4, no. (\%) & $12(3.92 \%)$ \\
\hline Centrum semiovale PVS, median (IQR) & $2(1-2)$ \\
\hline Rating 0, no. (\%) & 11 (3.59\%) \\
\hline Rating 1, no. (\%) & $141(46.08 \%)$ \\
\hline Rating 2, no. (\%) & $95(31.05 \%)$ \\
\hline Rating 3, no. (\%) & $49(16.01 \%)$ \\
\hline Rating 4, no. (\%) & $10(3.27 \%)$ \\
\hline Periventricular WMH Fazekas score, median (IQR) & $2(1-2)$ \\
\hline Grade 0, no. (\%) & $14(4.58 \%)$ \\
\hline Grade 1, no. (\%) & $104(33.99 \%)$ \\
\hline Grade 2, no. (\%) & $126(41.18 \%)$ \\
\hline Grade 3, no. (\%) & $62(20.26 \%)$ \\
\hline Deep WMH Fazekas score, median (IQR) & $1(1-2)$ \\
\hline Grade 0, no. (\%) & $39(12.75 \%)$ \\
\hline Grade 1, no. (\%) & $116(37.91 \%)$ \\
\hline Grade 2, no. (\%) & $114(37.25 \%)$ \\
\hline Grade 3, no. (\%) & 37 (12.09\%) \\
\hline Microbleeds, median (IQR) & $1(0-3)$ \\
\hline Presence of microbleeds, no. (\%) & $156(50.98 \%)$ \\
\hline 1 microbleed, no. (\%) & $58(18.95 \%)$ \\
\hline 2-4 microbleeds, no. (\%) & $56(18.30 \%)$ \\
\hline >5 microbleeds, no. (\%) & $42(13.73 \%)$ \\
\hline Strictly deep microbleeds, no. (\%) & $64(20.92 \%)$ \\
\hline Strictly lobar microbleeds, no. (\%) & $13(4.25 \%)$ \\
\hline Lacune, median (IQR) & $0(0-2)$ \\
\hline Presence of lacunes, $n$ (\%) & $133(43.46 \%)$ \\
\hline
\end{tabular}

$D B P$, diastolic blood pressure; IQR, interquartile range; PVS, enlarged perivascular spaces; SBP, systolic blood pressure; SD, standard deviation; SVD, small vessel disease; WMH, white matter hyperintensities. Ever smokers indicate current and previous smokers. Other heart disease does not include myocardial infarction and heart failure.
TABLE 2 | Comparison of characteristics between patients with high and low degree of PVS in the BG region.

\begin{tabular}{|c|c|c|c|}
\hline Characteristic & $\begin{array}{l}\text { High BG } \\
\text { PVS degree }\end{array}$ & $\begin{array}{c}\text { Low BG PVS } \\
\text { degree }\end{array}$ & $p$-value \\
\hline Demographics & $\begin{array}{c}(\mathrm{BG} P V S>2 \\
n=51)\end{array}$ & $\begin{array}{c}(B G P V S \leq 2 \\
n=205)\end{array}$ & \\
\hline Mean age in years (SD) & $64.53(10.73)$ & $54.29(13.08)$ & $p<0.001$ \\
\hline Male gender no. (\%) & 39 (76.47\%) & $180(70.59 \%)$ & $p=0.395$ \\
\hline \multicolumn{4}{|l|}{ VASCULAR RISK FACTORS } \\
\hline Ever-smokers no. (\%) & 27 (52.94\%) & $127(49.80 \%)$ & $p=0.682$ \\
\hline Alcohol drinking no. (\%) & $29(56.86 \%)$ & 125 (49.02\%) & $p=0.306$ \\
\hline Hypertension no. (\%) & $38(74.51 \%)$ & 186 (72.94\%) & $p=0.817$ \\
\hline Diabetes mellitus no. (\%) & $6(11.76 \%)$ & $36(14.12 \%)$ & $p=0.656$ \\
\hline Hyperlipidemia no. (\%) & $10(19.61 \%)$ & $24(9.41 \%)$ & $p=0.034$ \\
\hline $\begin{array}{l}\text { Prior cerebral infarction no. } \\
\text { (\%) }\end{array}$ & $10(19.61 \%)$ & $34(13.33 \%)$ & $p=0.244$ \\
\hline $\begin{array}{l}\text { Prior intracerebral } \\
\text { hemorrhage no. (\%) }\end{array}$ & $1(1.96 \%)$ & $6(2.35 \%)$ & $p=1.000$ \\
\hline $\begin{array}{l}\text { Prior subarachnoid } \\
\text { hemorrhage no. (\%) }\end{array}$ & $1(1.96 \%)$ & $0(0.00 \%)$ & $p=0.167$ \\
\hline Artial fibrillation no. (\%) & $1(1.96 \%)$ & $1(0.39 \%)$ & $p=3.060$ \\
\hline Other heart disease no. (\%) & $2(3.92 \%)$ & $11(4.31 \%)$ & $p=1.000$ \\
\hline Mean baseline SBP (SD) & $\begin{array}{l}157.51 \\
(20.41)\end{array}$ & $\begin{array}{l}164.75 \\
(24.67)\end{array}$ & $p=0.049$ \\
\hline Mean baseline DBP (SD) & $91.63(15.65)$ & $96.13(17.82)$ & $p=0.094$ \\
\hline \multicolumn{4}{|l|}{ SVD MARKERS } \\
\hline CS PVS median (IQR) & $2(1-3)$ & $1(1-2)$ & I \\
\hline High degree CS PVS, no. (\%) & 20 (39.22\%) & 39 (15.29\%) & $p<0.001$ \\
\hline $\begin{array}{l}\text { Periventricular WMH Fazekas } \\
\text { score, median (IQR) }\end{array}$ & $2(2-3)$ & $2(1-2)$ & / \\
\hline $\begin{array}{l}\text { Extensive periventricular } \\
\text { WMH }(\text { score }=3) \text {, no. }(\%)\end{array}$ & $24(47.06 \%)$ & $38(14.90 \%)$ & $p<0.001$ \\
\hline $\begin{array}{l}\text { Deep WMH Fazekas score, } \\
\text { median (IQR) }\end{array}$ & $2(2-3)$ & $2(1-2)$ & / \\
\hline $\begin{array}{l}\text { Extensive deep WMH (score } \\
\geq 2 \text { ), no. (\%) }\end{array}$ & $24(47.06 \%)$ & $38(14.90 \%)$ & $p<0.001$ \\
\hline Microbleeds, median (IQR) & $2(1-7)$ & $0(0-2)$ & / \\
\hline $\begin{array}{l}\text { Presence of microbleeds, no. } \\
\text { (\%) }\end{array}$ & 39 (76.47\%) & 117 (45.88\%) & $p<0.001$ \\
\hline $\begin{array}{l}\text { Strictly deep microbleeds, no. } \\
(\%)\end{array}$ & $13(25.49 \%)$ & $51(20.00 \%)$ & $p=0.379$ \\
\hline $\begin{array}{l}\text { Strictly lobar microbleeds, no. } \\
(\%)\end{array}$ & $2(3.92 \%)$ & $11(4.31 \%)$ & $p=1.000$ \\
\hline Lacunes, median (IQR) & $1(0-3)$ & $0(0-1)$ & / \\
\hline Presence of lacunes, no. (\%) & 32 (62.75\%) & $101(39.61 \%)$ & $p=0.002$ \\
\hline
\end{tabular}

$B G$, basal ganglia; CS, centrum semiovale; DBP, diastolic blood pressure; IQR, interquartile range; PVS, enlarged perivascular spaces; SBP, systolic blood pressure; $S D$, standard deviation; $S V D$, small vessel disease; $W M H$, white matter hyperintensities. Ever smokers indicate current and previous smokers. Other heart disease does not include myocardial infarction and heart failure. Extensive periventricular WMH indicates periventricular WMH Fazekas score 3 and extensive deep WMH indicates deep Fazekas scores 2-3.

$0.001)$ and presence of lacunes $(p=0.002)$. High degrees of BG PVS were associated with the presence of CMB $(p<0.001)$, but not with strictly deep CMB $(p=0.379)$ or strictly lobar $\mathrm{CMB}(p=1.000)$. 
In multivariable logistic regression analysis (Table 4), increasing age $(\mathrm{OR}=1.075 ; 95 \% \mathrm{CI}=1.038-1.113, p<0.001)$ was an independent predictor of increased BG PVS severity, after adjusting for gender and hypertension. The association between high degrees of BG PVS and high CS PVS degrees (OR $=6.906 ; 95 \% \mathrm{CI}=3.024-15.774, p<0.001)$, extensive $\mathrm{WMH}$ in periventricular region $(\mathrm{OR}=2.878 ; 95 \% \mathrm{CI}=1.298-6.379$, $p=0.009)$, the presence of $\mathrm{CMB}(\mathrm{OR}=4.073,95 \% \mathrm{CI}=$ 1.869-8.877, $p<0.001$ ) remained significant after adjustment for age, gender, and hypertension.

\section{Predictors of Increased CS PVS Severity in Spontaneous ICH Patients}

Demographic, vascular, and radiological characteristics of patients with high and low CS PVS degree are compared in Table 3. In univariable analyses, severe CS PVS were associated with the male gender $(p=0.030)$, an alcohol-drinking habit $(p=$ $0.007)$, and hyperlipidemia history $(p=0.001)$. High degrees of CS PVS were also associated with high degrees of BG PVS ( $p<$ $0.001)$ and the presence of strictly lobar CMB $(p=0.012)$.

In multivariable logistic regression analysis (Table 4), an alcohol-drinking habit $(\mathrm{OR}=2.805 ; 95 \% \mathrm{CI}=1.451-5.422, p=$ $0.002)$ and hyperlipidemia history $(\mathrm{OR}=3.782$; $95 \% \mathrm{CI}=1.582-$ 8.783, $p=0.003$ ) were independent predictors of increased CS PVS severity, after adjusting for age, gender, and hypertension. The association between high CS PVS degrees and high BG PVS degrees $(\mathrm{OR}=6.293$; 95\% $\mathrm{CI}=2.755-14.371, p<0.001)$ and the presence of strictly lobar CMB $(\mathrm{OR}=2.556,95 \% \mathrm{CI}=$ $1.285-5.085, p=0.008$ ) remained significant.

\section{DISCUSSION}

In this consecutive cohort of spontaneous ICH patients, we find that MR-visible BG PVS and CS PVS are closely coassociated. BG PVS severity is independently associated with increasing age, extensive periventricular $\mathrm{WMH}$ and presence of MB. CS PVS severity is associated with alcohol-drinking habit, hypercholesterolemia history, and the presence of strictly lobar MB.

Our results are in agreement with previous studies that BG and CS PVS are closely co-associated. There was a significant relationship between BG PVS and CS PVS severity in healthy elderly subjects (26) or in patients with acute ischemic stroke (IS) or TIA $(10,13,27)$. However, a previous study described no statistically significant association between BG PVS and CS PVS severity in spontaneous ICH patients (19). PVS functions as fluid circulation and drainage pathways for efficient exchange of essential nutrients and efficient removal of metabolic waste and cell debris through the central nervous system, and form part of the glymphatic system (28). Both visibility of BG PVS and CS PVS on MRI could be considered as a marker of dysfunctional perivascular flow, impaired nutrient change and waste flushing (29). In parallel, the arterial wall thickening and stiffening occurring with aging or hypertension impairs normal perivascular fluid flushing, facilitating dilation of PVS $(30,31)$. The dysfunction of the blood-brain barrier might contribute to
TABLE 3 | Comparison of characteristics between patients with high and low degree of PVS in the CS region.

\begin{tabular}{|c|c|c|c|}
\hline Characteristic & $\begin{array}{l}\text { High CS PVS } \\
\text { degree }\end{array}$ & $\begin{array}{l}\text { Low CS PVS } \\
\text { degree }\end{array}$ & $p$-value \\
\hline Demographics & $\begin{array}{c}(\mathrm{CS} P V S>2 \\
\quad n=59)\end{array}$ & $\begin{array}{c}(\mathrm{CS} P \vee S \leq 2 \\
n=247)\end{array}$ & \\
\hline Mean age in years (SD) & $54.58(12.12)$ & $56.34(13.59)$ & $p=0.361$ \\
\hline Male gender no. (\%) & 49 (83.05\%) & $170(68.83 \%)$ & $p=0.030$ \\
\hline \multicolumn{4}{|l|}{ VASCULAR RISK FACTORS } \\
\hline Ever-smokers no. (\%) & $28(47.46 \%)$ & $126(51.01 \%)$ & $p=0.624$ \\
\hline Alcohol drinking no. (\%) & $39(66.10 \%)$ & $115(46.56 \%)$ & $p=0.007$ \\
\hline Hypertension no. (\%) & 42 (71.19\%) & $182(73.68 \%)$ & $p=0.697$ \\
\hline Diabetes mellitus no. (\%) & $11(18.64 \%)$ & $31(12.55 \%)$ & $p=0.222$ \\
\hline Hyperlipidemia no. (\%) & $14(23.73 \%)$ & $20(8.10 \%)$ & $p=0.001$ \\
\hline $\begin{array}{l}\text { Prior cerebral infarction no. } \\
\text { (\%) }\end{array}$ & 9 (15.25\%) & $35(14.17 \%)$ & $p=0.831$ \\
\hline $\begin{array}{l}\text { Prior intracerebral } \\
\text { hemorrhage no. (\%) }\end{array}$ & $2(3.39 \%)$ & $5(2.02 \%)$ & $p=0.528$ \\
\hline $\begin{array}{l}\text { Prior subarachnoid } \\
\text { hemorrhage no. (\%) }\end{array}$ & $1(1.69 \%)$ & $0(0.00 \%)$ & $p=0.93$ \\
\hline Artial fibrillation no. (\%) & $1(1.69 \%)$ & $1(0.40 \%)$ & $p=0.349$ \\
\hline Other heart disease no. (\%) & $3(5.08 \%)$ & $10(4.05 \%)$ & $p=0.723$ \\
\hline Mean baseline SBP (SD) & $\begin{array}{l}164.05 \\
(22.90)\end{array}$ & $\begin{array}{l}163.46 \\
(24.47)\end{array}$ & $p=0.867$ \\
\hline Mean baseline DBP (SD) & 98.39 (19.59) & $94.66(16.96)$ & $p=0.143$ \\
\hline \multicolumn{4}{|l|}{ SVD MARKERS } \\
\hline BG PVS median (IQR) & $2(1-3)$ & $1(1-2)$ & / \\
\hline High degree BG PVS, no. (\%) & $20(33.90 \%)$ & $31(12.55 \%)$ & $p<0.001$ \\
\hline $\begin{array}{l}\text { Periventricular WMH Fazekas } \\
\text { score, median (IQR) }\end{array}$ & $2(1-2)$ & $2(1-2)$ & / \\
\hline $\begin{array}{l}\text { Extensive periventricular } \\
\text { WMH (score = 3), no. (\%) }\end{array}$ & $9(15.25 \%)$ & $53(21.46 \%)$ & $p=0.287$ \\
\hline $\begin{array}{l}\text { Deep WMH Fazekas score, } \\
\text { median (IQR) }\end{array}$ & $2(1-2)$ & $1(1-2)$ & / \\
\hline $\begin{array}{l}\text { Extensive deep WMH (score } \\
\geq 2 \text { ), no. (\%) }\end{array}$ & 34 (57.63\%) & $117(47.37 \%)$ & $p=0.157$ \\
\hline Microbleeds, median (IQR) & $1(0-2)$ & $1(0-3)$ & / \\
\hline $\begin{array}{l}\text { Presence of microbleeds, no. } \\
\text { (\%) }\end{array}$ & 30 (50.85\%) & $126(51.01 \%)$ & $p=0.982$ \\
\hline $\begin{array}{l}\text { Strictly deep microbleeds, no. } \\
(\%)\end{array}$ & $13(22.03 \%)$ & $51(20.65 \%)$ & $p=0.814$ \\
\hline $\begin{array}{l}\text { Strictly lobar microbleeds, no. } \\
(\%)\end{array}$ & $6(10.17 \%)$ & $7(2.83 \%)$ & $p=0.012$ \\
\hline Lacunes, median (IQR) & $1(1-2)$ & $0(0-2)$ & / \\
\hline Presence of lacunes, no. (\%) & $30(50.85 \%)$ & $103(41.70 \%)$ & $p=0.203$ \\
\hline
\end{tabular}

$B G$, basal ganglia; CS, centrum semiovale; DBP, diastolic blood pressure; IQR, interquartile range; PVS, enlarged perivascular spaces; SBP, systolic blood pressure; $S D$, standard deviation; SVD, small vessel disease; WMH, white matter hyperintensities. Ever smokers indicate current and previous smokers. Other heart disease does not include myocardial infarction and heart failure. Extensive periventricular WMH indicates periventricular WMH Fazekas score 3 and extensive deep WMH indicates deep Fazekas scores 2-3.

the dilation of PVS in both regions (29). A variety of study groups show advancing age is the strongest independent risk factor for PVS in both BG and CS regions in healthy elderly subjects (9), in IS patients (10), and in patients with CAA-ICH patients (19). Our results are in line with these previous studies that we find BG PVS 
TABLE 4 | Univariable and multivariable associations for high degree of BG PVS and high degree of CS PVS.

\begin{tabular}{|c|c|c|}
\hline & $\begin{array}{l}\text { Unadjusted OR ( } 95 \% \\
\text { Cl), } p \text {-value }\end{array}$ & $\begin{array}{c}\text { Adjusted OR }(95 \% \mathrm{Cl}), \\
p \text {-value }\end{array}$ \\
\hline \multicolumn{3}{|c|}{ HIGH DEGREE OF BG PVS } \\
\hline Age & $\begin{array}{c}1.070(1.041-1.100) \\
p<0.001\end{array}$ & $\begin{array}{c}1.075(1.038-1.113) \\
p<0.001\end{array}$ \\
\hline High CS PVS degree & $\begin{array}{c}3.573(1.851-6.896) \\
p<0.001\end{array}$ & $\begin{array}{c}6.906(3.024-15.774) \\
p<0.001\end{array}$ \\
\hline $\begin{array}{l}\text { Extensive periventricular } \\
\text { WMH }\end{array}$ & $\begin{array}{c}5.076(2.653-9.713) \\
p<0.001\end{array}$ & $\begin{array}{c}2.878(1.298-6.379) \\
p=0.009\end{array}$ \\
\hline Presence of microbleeds & $\begin{array}{c}3.833(1.918-7.660) \\
p<0.001\end{array}$ & $\begin{array}{c}4.073(1.869-8.877) \\
p<0.001\end{array}$ \\
\hline \multicolumn{3}{|c|}{ HIGH DEGREE OF CS PVS } \\
\hline Alcohol drinking & $\begin{array}{c}2.792(1.455-5.358) \\
p=0.002\end{array}$ & $\begin{array}{c}2.805(1.451-5.422) \\
p=0.002\end{array}$ \\
\hline Hyperlipidemia & $\begin{array}{c}3.265(1.424-7.485) \\
p=0.005\end{array}$ & $\begin{array}{c}3.728(1.582-8.783) \\
p=0.003\end{array}$ \\
\hline High BG PVS degree & $\begin{array}{c}4.299(2.030-9.102) \\
p<0.001\end{array}$ & $\begin{array}{c}6.293(2.755-14.371) \\
p<0.001\end{array}$ \\
\hline Strictly lobe microbleeds & $\begin{array}{c}2.422(1.229-4.773) \\
p=0.011\end{array}$ & $\begin{array}{c}2.556(1.285-5.085) \\
p=0.008\end{array}$ \\
\hline
\end{tabular}

BG, basal ganglia; $\mathrm{Cl}$, confidence interval; CS, centrum semiovale; OR, odds ratio; PVS, enlarged perivascular spaces; WMH, white matter hyperintensities. Age effects are presented per year. Multivariable logistic regression model adjusted for age, gender, and hypertension.

is associated with increasing age in this cohort of spontaneous ICH patients, but we did not find the same association between increasing age and CS PVS severity. This difference may relate to different brain integrity status, underlying pathophysiological processes and genotypes among patients $(26,32)$.

We identified a positive association between BG PVS severity and extensive periventricular $\mathrm{WMH}$ in $\mathrm{ICH}$ patients after adjusting for age, gender and hypertension. Arba et al. (13) found that in patients with IS or TIA, BG PVS severity was associated with WMH severity in both periventricular and deep regions. In another group of IS and TIA patients, Hurford et al. (33) found severe WMH was independently associated with BG PVS severity, however, they did not specify the WMH regions and used a different $\mathrm{WMH}$ visual rating scale. In a large memory clinic cohort, both high degrees of BG PVS and CS PVS were associated with moderate-to-severe WMH after adjustment and they did not specify the periventricular and deep WMH either (34). In the Kashima Scan Study, BG PVS severity was associated with severe WMH but not periventricular WMH (35) in neurologically healthy adults. In a recent published systematic review and meta-analysis about the association between PVS and neuroimaging features, the association between PVS and WMH was not significant in the meta-analysis though the direction is positive (36) and the PVS-WMH associations may reflect differences in population characteristics or shared coassociations. Increased WMH burden is associated with bloodbrain barrier dysfunction in patients with SVD (37-39). The blood-brain barrier dysfunction might facilitate dilation of PVS, endothelial dysfunction, and impair further nutrient transport. Endothelial dysfunction blocked oligodendrocyte precursor cell maturation, thereby causing direct damage to myelin and myelin repairment $(40,41)$. The blood-brain barrier dysfunction might contribute to both BG PVS severity and extensive periventricular WMH (29).

Our study suggested the association between PVS and CMB varied by regions. We found the BG PVS severity was associated with the presence of CMB (at least one microbleed appearing at any region) and the CS PVS severity as associated with the presence of strictly lobar CMB. Our study agrees with previous studies that CS PVS severity was associated with strictly lobar $\mathrm{CMB}$ in neurologically healthy adults (35) and increased lobar CMB count was an independent predictor of high CS PVS degrees in a memory clinic cohort (42). However, in this study we did not find the association between the BG PVS severity and strictly deep CMB observed in previous studies including in ICH patients (19) and in a large memory clinic cohort (34). Currently there were insufficient data to compare PVS and CMB by locations (36), and the association between PVS and CMB in different locations merits attention in future studies.

We identified that current alcohol-drinking status is significantly associated with CS PVS severity in ICH patients after adjusting for age, gender, and hypertension. Other groups have studied alcohol intake and the risk of ICH and SVD. Heavy alcohol intake (more than $300 \mathrm{~g}$ alcohol per week) was associated with the spontaneous ICH occurrence at a younger age (43) and deep CMB incident in a population-based study (44). Current alcohol-drinking status was associated with $\mathrm{WMH}$ volume in acute ischemic stroke patients (45) and silent brain infarction in community-dwelling elderly people (46). In this study, we recorded the patient current alcohol drinking status instead of alcohol consumed in grams, in accordance with the suggestion that consuming zero standard drinks, daily, minimizes health risks, from the UK's chief medical officer guidelines (47) and the global burden of disease 2016 (48).

We found a positive association between hypercholesterolemia history and severe CS PVS degree in ICH patients; however, a previous study found higher blood total cholesterol levels was inversely associated with PVS severity in CS region in healthy elderly subjects (9). Interestingly, previous studies suggested hypercholesterolemia might play a protective role in SVD features such as WMH and infarction: IS patients and control participants with hypercholesterolemia history had less severe WMH (49); IS patients with high triglyceride levels had less WMH severity (50) and higher blood total cholesterol levels were significantly associated with a lower risk of WMH and lacunar infarction in participants aged 40 and over (51). The link between PVS severity and hypercholesterolemia history or blood cholesterol levels deserves more attention and further investigations.

Major strengths of our study include a large consecutive cohort of spontaneous ICH patients which were reviewed by ICH panel experts; furthermore, we used a highly standardized SVD visual methodology and were blinded to patients' clinical information and risk factor profiles to avoid rating bias. Potential limitations are in the study design. This cohort only consists of patients with spontaneous ICH with good quality MRI scans (after actively excluding patients diagnosed with secondary ICH), 
and a potential limitation is the lack of a control group with agematched healthy patients which might limit the generalizability of the results. Another limitation is that the cohort is not gender balanced; it consists of mainly male patients (72\%). We planned to include all unselected consecutive patients referred to the stroke unit who underwent MRI, however, many patients with ICH could not undergo MRI for being too sick or with contraindications, which led to a potential for selection bias. All patients were randomly allocated to two different MRI scanners due to the availability, which might be a potential source of image heterogeneity. However, two scanners have the same field strengths and similar ICH scanning protocols that limit image heterogeneity influencing the ratings. We only rated the PVS in $\mathrm{BG}$ and CS regions, however, we did not rate the PVS in the midbrain because there were few numbers of slices on which midbrain PVS appear and its rating agreement was influenced by the limited slice number and partial volume effect. We did not include the hippocampus region because of its visualization on axial images varied and may be confused with normal variants hippocampal fissural cysts as suggested previously (52). However, we rated the BG and CS PVS using a validated scale widely used in stroke and SVD studies $(10,21)$ and we reviewed all available slices instead of a typical one slice in order to increase rating accuracy. Future validation and confirmation of these results in larger, prospective cohorts will be needed to surmount these sampling biases and current limitations.

The present study provides preliminary evidence for the risk factors and neuroimaging features for MR-visible PVS in spontaneous ICH patients, which are age, periventricular WMH, and presence of microbleeds in the BG region and alcoholdrinking habit, hypercholesterolemia history, and strictly lobar microbleeds in the CS region. These factors have potential applications for PVS in clinical research or clinical trials and may be an efficient way to explore the biological mechanisms underlying PVS in ICH patients. Further studies are needed to explore the mechanism and clinical importance of PVS, with possible implications for cerebrovascular disease prevention.

\section{REFERENCES}

1. van Asch CJ, Luitse MJ, Rinkel GJ, van der Tweel I, Algra A, Klijn CJ. Incidence, case fatality, and functional outcome of intracerebral haemorrhage over time, according to age, sex, and ethnic origin: a systematic review and meta-analysis. Lancet Neurol. (2010) 9:167-76. doi: 10.1016/S1474-4422(09)70340-0

2. Qureshi AI, Mendelow AD, Hanley DF. Intracerebral haemorrhage. Lancet. (2009) 373:1632-44. doi: 10.1016/S0140-6736(09)60371-8

3. Kwee RM, Kwee TC. Virchow-Robin spaces at MR imaging. Radiographics. (2007) 27:1071-86. doi: 10.1148/rg.274065722

4. Etemadifar M, Hekmatnia A, Tayari N, Kazemi M, Ghazavi A, Akbari $\mathrm{M}$, et al. Features of Virchow-Robin spaces in newly diagnosed multiple sclerosis patients. Eur J Radiol. (2011) 80:e104-8. doi: 10.1016/j.ejrad.2010. 05.018

5. Wardlaw JM, Smith EE, Biessels GJ, Cordonnier C, Fazekas F, Frayne R, et al. Neuroimaging standards for research into small vessel disease and its contribution to ageing and neurodegeneration. Lancet Neurol. (2013) 12:822-38. doi: 10.1016/S1474-4422(13)70124-8

\section{DATA AVAILABILITY}

All datasets generated for this study are included in the manuscript and/or the supplementary files.

\section{ETHICS STATEMENT}

All 306 patients participating in this study provided written informed consent. The Beijing Tiantan Hospital Ethics Committee approved this study.

\section{AUTHOR CONTRIBUTIONS}

$\mathrm{XW}$ and $\mathrm{XZ}$ designed the study and drafted the manuscript. HF and YW collected the clinical data and managed the database. JZ collected the imaging data in this study. All authors approved for the manuscript submitted.

\section{FUNDING}

The ICH project was conducted under a China National Key R\&D Program Funding (Beijing Municipal Science and Technology Commission, No. Z161100002616008), and supported by National Key Research and Development Program of China (No. 2018YFC1312200), Beijing Municipal Administration of Hospitals' Apex Plan (No. DFL20150501), and National Science and Technology Major Project (2017ZX09304018). XW was supported by China Postdoctoral Science Foundation (No. 2017M620835) and Beijing Postdoctoral Research Foundation (2017-22-119).

\section{ACKNOWLEDGMENTS}

We thank all the participants for their important contributions in this study. This manuscript has not been published elsewhere in whole or in part.

6. Abbott NJ, Pizzo ME, Preston JE, Janigro D, Thorne RG. The role of brain barriers in fluid movement in the CNS: is there a 'glymphatic' system? Acta Neuropathol. (2018) 135:387-407. doi: 10.1007/s00401-018-1812-4

7. Nedergaard M. Neuroscience. Garbage truck of the brain. Science. (2013) 340:1529-30. doi: 10.1126/science.1240514

8. Smith AJ, Verkman AS. The "glymphatic" mechanism for solute clearance in Alzheimer's disease: game changer or unproven speculation? FASEB J. (2018) 32:543-51. doi: 10.1096/fj.201700999

9. Zhu YC, Tzourio C, Soumare A, Mazoyer B, Dufouil C, Chabriat H. Severity of dilated Virchow-Robin spaces is associated with age, blood pressure, and MRI markers of small vessel disease: a populationbased study. Stroke. (2010) 41:2483-90. doi: 10.1161/STROKEAHA.110.5 91586

10. Potter GM, Doubal FN, Jackson CA, Chappell FM, Sudlow CL, Dennis MS, et al. Enlarged perivascular spaces and cerebral small vessel disease. Int J Stroke. (2015) 10:376-81. doi: 10.1111/ijs.12054

11. Aribisala BS, Wiseman S, Morris Z, Valdes-Hernandez MC, Royle NA, Maniega SM, et al. Circulating inflammatory markers are associated with magnetic resonance imaging-visible perivascular spaces but not 
directly with white matter hyperintensities. Stroke. (2014) 45:605-7. doi: 10.1161/STROKEAHA.113.004059

12. Maclullich AM, Wardlaw JM, Ferguson KJ, Starr JM, Seckl JR, Deary IJ. Enlarged perivascular spaces are associated with cognitive function in healthy elderly men. J Neurol Neurosurg Psychiatry. (2004) 75:1519-23. doi: 10.1136/jnnp.2003.030858

13. Arba F, Quinn TJ, Hankey GJ, Lees KR, Wardlaw JM, Ali M, et al. Enlarged perivascular spaces and cognitive impairment after stroke and transient ischemic attack. Int J Stroke. (2018) 13:47-56. doi: 10.1177/1747493016666091

14. Banerjee G, Kim HJ, Fox Z, Jager HR, Wilson D, Charidimou A, et al. MRI-visible perivascular space location is associated with Alzheimer's disease independently of amyloid burden. Brain. (2017) 140:1107-16. doi: 10.1093/brain/awx003

15. Chen S, Yang Q, Chen G, Zhang JH. An update on inflammation in the acute phase of intracerebral hemorrhage. Transl Stroke Res. (2015) 6:4-8. doi: 10.1007/s12975-014-0384-4

16. Wuerfel J, Haertle M, Waiczies H, Tysiak E, Bechmann I, Wernecke KD, et al. Perivascular spaces-MRI marker of inflammatory activity in the brain? Brain. (2008) 131:2332-40. doi: 10.1093/brain/awn171

17. Polledo L, Gonzalez J, Benavides J, Martinez-Fernandez B, Ferreras MC, Marin JF. Perivascular inflammatory cells in ovine Visna/maedi encephalitis and their possible role in virus infection and lesion progression. J Neurovirol. (2012) 18:532-7. doi: 10.1007/s13365-012-0131-0

18. Sagar D, Lamontagne A, Foss CA, Khan ZK, Pomper MG, Jain P. Dendritic cell CNS recruitment correlates with disease severity in EAE via CCL2 chemotaxis at the blood-brain barrier through paracellular transmigration and ERK activation. J Neuroinflammation. (2012) 9:245. doi: 10.1186/1742-2094-9-245

19. Charidimou A, Meegahage R, Fox Z, Peeters A, Vandermeeren Y, Laloux P, et al. Enlarged perivascular spaces as a marker of underlying arteriopathy in intracerebral haemorrhage: a multicentre MRI cohort study. $J$ Neurol Neurosurg Psychiatry. (2013) 84:624-9. doi: 10.1136/jnnp-2012-304434

20. Charidimou A, Boulouis G, Pasi M, Auriel E, van Etten ES, Haley K, et al. MRI-visible perivascular spaces in cerebral amyloid angiopathy and hypertensive arteriopathy. Neurology. (2017) 88:1157-64. doi: 10.1212/WNL.0000000000003746

21. Potter GM, Chappell FM, Morris Z, Wardlaw JM. Cerebral perivascular spaces visible on magnetic resonance imaging: development of a qualitative rating scale and its observer reliability. Cerebrovasc Dis. (2015) 39:224-31. doi: $10.1159 / 000375153$

22. Fazekas F, Chawluk JB, Alavi A, Hurtig HI, Zimmerman RA. MR signal abnormalities at $1.5 \mathrm{~T}$ in Alzheimer's dementia and normal aging. AJR Am J Roentgenol. (1987) 149:351-6. doi: 10.2214/ajr.149.2.351

23. Gregoire SM, Chaudhary UJ, Brown MM, Yousry TA, Kallis C, Jager HR, et al. The Microbleed Anatomical Rating Scale (MARS): reliability of a tool to map brain microbleeds. Neurology. (2009) 73:1759-66. doi: 10.1212/WNL.0b013e3181c34a7d

24. Staals J, Makin SD, Doubal FN, Dennis MS, Wardlaw JM. Stroke subtype, vascular risk factors, and total MRI brain small-vessel disease burden. Neurology. (2014) 83:1228-34. doi: 10.1212/WNL.0000000000000837

25. Staals J, Booth T, Morris Z, Bastin ME, Gow AJ, Corley J, et al. Total MRI load of cerebral small vessel disease and cognitive ability in older people. Neurobiol Aging. (2015) 36:2806-11. doi: 10.1016/j.neurobiolaging.2015.06.024

26. Duperron MG, Tzourio C, Sargurupremraj M, Mazoyer B, Soumare A, Schilling S, et al. Burden of dilated perivascular spaces, an emerging marker of cerebral small vessel disease, is highly heritable. Stroke. (2018) 49:282-7. doi: 10.1161/STROKEAHA.117.019309

27. Zhang C, Chen Q, Wang Y, Zhao X, Wang C, Liu L, et al. Risk factors of dilated Virchow-Robin spaces are different in various brain regions. PLoS ONE. (2014) 9:e105505. doi: 10.1371/journal.pone.0105505

28. Rasmussen MK, Mestre H, Nedergaard M. The glymphatic pathway in neurological disorders. Lancet Neurol. (2018) 17:1016-24. doi: 10.1016/S1474-4422(18)30318-1

29. Wardlaw JM, Smith C, Dichgans M. Small vessel disease: mechanisms and clinical implications. Lancet Neurol. (2019) 18:684-96. doi: 10.1016/S1474-4422(19)30079-1

30. Iliff J, Wang M, Zeppenfeld DM, Venkataraman A, Plog BA, Liao $\mathrm{Y}$, et al. Cerebral arterial pulsation drives paravascular CSF-interstitial fluid exchange in the murine brain. $J$ Neurosci. (2013) 33:18190-9. doi: 10.1523/JNEUROSCI.1592-13.2013

31. Mestre H, Tithof J, Du T, Song W, Peng W, Sweeney AM, et al. Flow of cerebrospinal fluid is driven by arterial pulsations and is reduced in hypertension. Nat Commun. (2018) 9:4878. doi: 10.1038/s41467-01807318-3

32. Charidimou A, Pantoni L, Love S. The concept of sporadic cerebral small vessel disease: a road map on key definitions and current concepts. Int J Stroke. (2016) 11:6-18. doi: 10.1177/1747493015607485

33. Hurford R, Charidimou A, Fox Z, Cipolotti L, Jager R, Werring DJ. MRIvisible perivascular spaces: relationship to cognition and small vessel disease MRI markers in ischaemic stroke and TIA. J Neurol Neurosurg Psychiatry. (2014) 85:522-5. doi: 10.1136/jnnp-2013-305815

34. Shams S, Martola J, Charidimou A, Larvie M, Granberg T, Shams M, et al. Topography and determinants of magnetic resonance imaging (MRI)-visible perivascular spaces in a large memory clinic cohort. J Am Heart Assoc. (2017) 6:e006279. doi: 10.1161/JAHA.117.006279

35. Yakushiji Y, Charidimou A, Hara M, Noguchi T, Nishihara M, Eriguchi $M$, et al. Topography and associations of perivascular spaces in healthy adults: the Kashima scan study. Neurology. (2014) 83:2116-23. doi: 10.1212/WNL.0000000000001054

36. Francis F, Ballerini L, Wardlaw JM. Perivascular spaces and their associations with risk factors, clinical disorders and neuroimaging features: a systematic review and meta-analysis. Int J Stroke. (2019) 14:359-71. doi: $10.1177 / 1747493019830321$

37. Huisa BN, Caprihan A, Thompson J, Prestopnik J, Qualls CR, Rosenberg GA. Long-term blood-brain barrier permeability changes in Binswanger disease. Stroke. (2015) 46:2413-8. doi: 10.1161/STROKEAHA.115.009589

38. Munoz Maniega S, Chappell FM, Valdes Hernandez MC, Armitage PA, Makin SD, Heye AK, et al. Integrity of normal-appearing white matter: influence of age, visible lesion burden and hypertension in patients with small-vessel disease. J Cereb Blood Flow Metab. (2017) 37:644-56. doi: $10.1177 / 0271678 X 16635657$

39. Zhang CE, Wong SM, Uiterwijk R, Backes WH, Jansen JFA, Jeukens C, et al. Blood-brain barrier leakage in relation to white matter hyperintensity volume and cognition in small vessel disease and normal aging. Brain Imaging Behav. (2019) 13:389-95. doi: 10.1007/s11682-018-9855-7

40. Bugiani M, Kevelam SH, Bakels HS, Waisfisz Q, Ceuterick-de Groote C, Niessen HW, et al. Cathepsin A-related arteriopathy with strokes and leukoencephalopathy (CARASAL). Neurology. (2016) 87:1777-86. doi: 10.1212/WNL.0000000000003251

41. Rajani RM, Quick S, Ruigrok SR, Graham D, Harris SE, Verhaaren BFJ, et al. Reversal of endothelial dysfunction reduces white matter vulnerability in cerebral small vessel disease in rats. Sci Transl Med. (2018) 10:eaam9507. doi: 10.1126/scitranslmed.aam9507

42. Martinez-Ramirez S, Pontes-Neto OM, Dumas AP, Auriel E, Halpin A, Quimby $M$, et al. Topography of dilated perivascular spaces in subjects from a memory clinic cohort. Neurology. (2013) 80:1551-6. doi: 10.1212/WNL.0b013e31828f1876

43. Casolla B, Dequatre-Ponchelle N, Rossi C, Henon H, Leys D, Cordonnier C. Heavy alcohol intake and intracerebral hemorrhage: characteristics and effect on outcome. Neurology. (2012) 79:1109-15. doi: 10.1212/WNL.0b013e3182698d00

44. Ding J, Sigurdsson S, Garcia M, Phillips CL, Eiriksdottir G, Gudnason $\mathrm{V}$, et al. Risk factors associated with incident cerebral microbleeds according to location in older people: the age, gene/environment susceptibility (AGES)-Reykjavik study. JAMA Neurol. (2015) 72:682-8. doi: 10.1001/jamaneurol.2015.0174

45. Cloonan L, Fitzpatrick KM, Kanakis AS, Furie KL, Rosand J, Rost NS. Metabolic determinants of white matter hyperintensity burden in patients with ischemic stroke. Atherosclerosis. (2015) 240:149-53. doi: 10.1016/j.atherosclerosis.2015.02.052

46. Fukuda K, Takashima Y, Hashimoto M, Uchino A, Yuzuriha T, Yao H. Early menopause and the risk of silent brain infarction in community-dwelling elderly subjects: the Sefuri brain MRI study. J Stroke Cerebrovasc Dis. (2014) 23:817-22. doi: 10.1016/j.jstrokecerebrovasdis.2013.07.005

47. Burton R, Sheron N. No level of alcohol consumption improves health. Lancet. (2018) 392:987-8. doi: 10.1016/S0140-6736(18)31571-X 
48. GBD 2016 Alcohol and Drug Use Collaborators. The global burden of disease attributable to alcohol and drug use in 195 countries and territories, 19902016: a systematic analysis for the Global Burden of Disease Study 2016. Lancet Psychiatry. (2018) 5:987-1012. doi: 10.1016/S2215-0366(18)30337-7

49. Jimenez-Conde J, Biffi A, Rahman R, Kanakis A, Butler C, Sonni $\mathrm{S}$, et al. Hyperlipidemia and reduced white matter hyperintensity volume in patients with ischemic stroke. Stroke. (2010) 41:437-42. doi: 10.1161/STROKEAHA.109.563502

50. Ke D, Zhou F, Liang H, Xu Y, Lou H. Hypertriglyceridemia is associated with reduced leukoaraiosis severity in patients with a small vessel stroke. Behav Neurol. (2018) 2018:1361780. doi: 10.1155/2018/1361780

51. Ohwaki K, Yano E, Tamura A, Inoue T, Saito I. Hypercholesterolemia is associated with a lower risk of cerebral ischemic small vessel disease detected on brain checkups. Clin Neurol Neurosurg. (2013) 115:669-72. doi: 10.1016/j.clineuro.2012.07.025
52. Adams HH, Cavalieri M, Verhaaren BF, Bos D, van der Lugt A, Enzinger C et al. Rating method for dilated Virchow-Robin spaces on magnetic resonance imaging. Stroke. (2013) 44:1732-5. doi: 10.1161/STROKEAHA.111.000620

Conflict of Interest Statement: The authors declare that the research was conducted in the absence of any commercial or financial relationships that could be construed as a potential conflict of interest.

Copyright (c) 2019 Wang, Feng, Wang, Zhou and Zhao. This is an open-access article distributed under the terms of the Creative Commons Attribution License (CC BY). The use, distribution or reproduction in other forums is permitted, provided the original author(s) and the copyright owner(s) are credited and that the original publication in this journal is cited, in accordance with accepted academic practice. No use, distribution or reproduction is permitted which does not comply with these terms. 